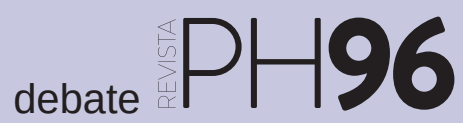

\title{
El patrimonio contemporáneo en la construcción de la memoria democrática. La arquitectura que pervivió a los cambios de régimen del siglo $\mathrm{XX}$
}

Juan-Andrés Rodríguez-Lora | Patrimonio y Desarrollo Urbano Territorial en Andalucía, Dpto. de Urbanística y Ordenación del Territorio, Universidad de Sevilla

URL de la contribución <www.iaph.es/revistaph/index.php/revistaph/article/view/4320>

Son numerosos los factores que pueden presentarse como un hándicap a la hora de patrimonializar la arquitectura que se construyó en el pasado siglo XX, especialmente la que respondía a conceptos nacidos desde el Racionalismo, el Movimiento Moderno y vinculados a las vanguardias históricas. A ello habría que sumar la componente de haber sido construida en la etapa de la Europa de los regímenes totalitarios.

Entre las múltiples negativas a reconocer estas arquitecturas como bienes culturales se encontrarían, por un lado, la relativa al tiempo necesario que debe transcurrir desde la construcción de un edificio hasta su reconocimiento patrimonial. Este valor temporal ha visto paulatinamente menguado su peso y longevidad con el paso de las múltiples leyes de patrimonio histórico que se han sucedido en nuestro ámbito geográfico. Pasando de valor imprescindible, e incluso de duración centenaria en las primeras leyes, a una reducción considerable del mismo, como así muestra el Plan Nacional de Conservación del Patrimonio Cultural del Siglo $X X$ (PLAN, 2015: 6).

Muy vinculado al hecho temporal, aparecería la particularidad de que se trata de elementos urbanos que se encuentran aún activos o lo han estado hasta hace poco con el cometido de responder a necesidades diarias de una sociedad contemporánea. Esta cotidianeidad implícita, sumada a un lenguaje despojado de ornato, pueden redundar en la ausencia de consideración de estos inmuebles como legado cultural, agudizándose en el caso de la población menos especializada en el concepto actual de patrimonio.
Habría que destacar, igualmente como obstáculo, el propio pensamiento de los arquitectos de los que surgen todas estas propuestas vanguardistas. Estos artífices modernos solían mostrarse beligerantes ante la idea de la pervivencia de los edificios una vez que han perdido su función, habitualmente con una postura crítica a la monumentalización (DE JONGE, 2017: 17).

Finalmente, otra de las dificultades que se presenta para estos casos es la relacionada con las connotaciones franquistas que pudieran emanar de los edificios construidos durante los años de régimen dictatorial. Este rechazo suele surgir bien a raíz de la simbología explícita que se colocaba en los edificios -cuestión abordada en la propia Ley 2/2017 en el artículo 32 de la misma (LEY 2/2017, 2017)-, o bien por ser edificios cuya construcción fuera promovida desde o durante el gobierno franquista, cuestión que sigue vigente en la actualidad y en que se centra la presente reflexión.

A pesar de lo explicitado anteriormente, los avances en el reconocimiento de esta arquitectura a nivel institucional e internacional cuentan con un recorrido que ya casi ronda el cincuentenario. Esta consideración por el patrimonio contemporáneo arrancaría en el año 1971, cuando numerosos expertos en esta materia se reunieron en Praga ante la preocupante desaparición de edificios del siglo XIX, pero también del siglo XX, abogando por su protección basándose en que "representan valores creadores que deben ser protegidos, de la misma forma que las creaciones de épocas precedentes" (DECLARACIÓN, 1971). Bien es cierto que, y no merecería ser pasado por alto, a efectos jurídicos, la pro- 

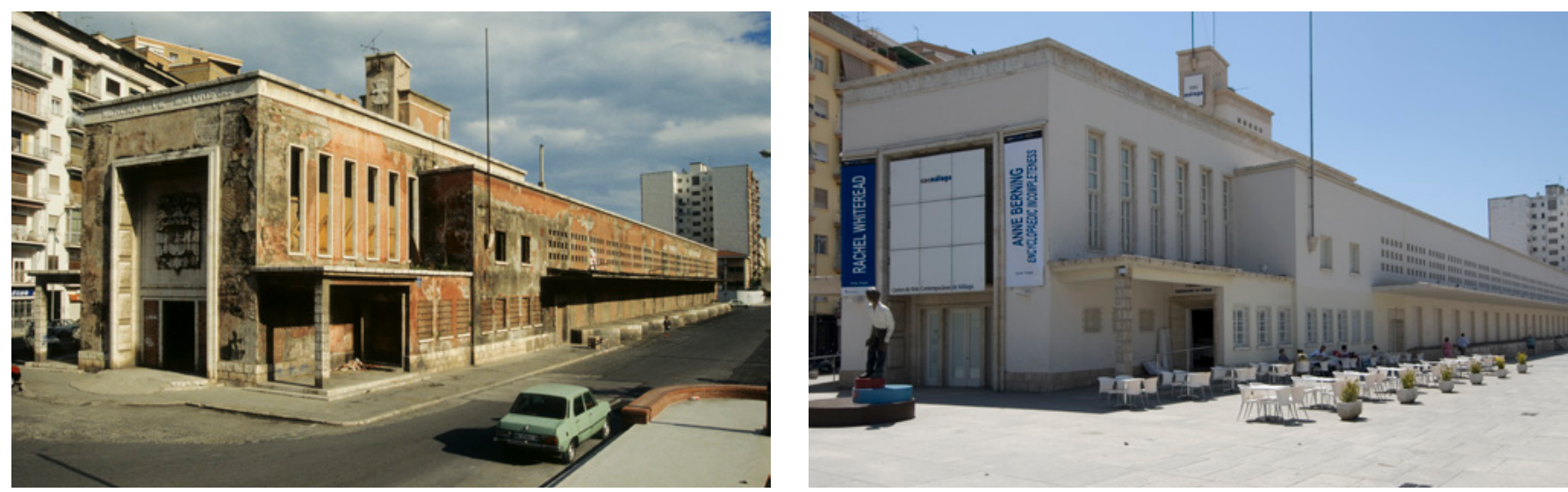

Mercado de Mayoristas en Málaga (1937-1944), de Luis Gutiérrez Soto, antes y después de su intervención, ejemplo de supresión de la simbología franquista una vez se interviene en democracia | fotos Fondo gráfico IAPH

tección que suelen recibir estos edificios por parte de las administraciones competentes en materia patrimonial es menor que la que otorgan a edificios de mayor recorrido histórico. Si pasamos al plano social, el reconocimiento patrimonial por parte de la población se encontraría en una situación aún más reducida.

Centrando la atención en la producción arquitectónica moderna del periodo de dictadura en España, son diversas las dificultades que en algunos casos pudieron encontrar estos proyectos a la hora de ser materializados. La apuesta por parte de distintos regímenes autoritarios por una arquitectura de aspecto más cercano al historicismo y con anhelos de monumentalidad tiene su reflejo en el caso español. La búsqueda de vínculos con tiempos pasados se topaba con el sentimiento rupturista que caracterizaba a las vanguardias. Este anacronismo provocado por la postura inicial del gobierno franquista se agudiza de manera especial en la arquitectura más oficialista, escenario con el que abocaron a múltiples arquitectos, con antecedentes y obras modernas de notable calidad (como es el caso del mercado de mayoristas de Málaga del arquitecto Luis Gutiérrez Soto), a construir edificios que no respondían a los conceptos desarrollados por la disciplina arquitectónica del momento (como el edificio que albergó el Ministerio del Aire en Madrid de 1943 a 1958, obra del mismo arquitecto).
Sin embargo, el proyecto moderno lograría en múltiples casos superar las dificultades de partida llegando a implantarse, incluso siendo aceptado y promovido, en el ámbito institucional y social de la época. De este modo, quedarían como legado para las generaciones posteriores ejemplos relevantes de arquitectura racionalista y moderna construida durante la dictadura. Como muestra de dicha trascendencia son diversos los edificios que se encuentran insertos en los inventarios especializados de este patrimonio.

En este sentido, a nivel peninsular destacarían los incluidos en el registro DOCOMOMO Ibérico y a nivel autonómico, para el caso de Andalucía, los del Registro Andaluz de Arquitectura Contemporánea (FERNÁNDEZ BACA-CASARES; PÉREZ ESCOLANO, 2012). Pero para construir una memoria democrática en torno a la arquitectura señalada también habría que mostrar, como así dilucidan las pertinentes investigaciones, las propuestas que no nacen en esta época, sino que se tratan de la continuidad de políticas y acciones que se habían venido haciendo en etapas previas. En este sentido se podría hacer referencia, entre otras, a la construcción de vivienda social, tema que venía preocupando en Europa desde finales del siglo XIX, como mostraron los congresos internacionales de "casas baratas", y cuyas medidas se comienzan a aplicar ya desde principios del XX (QUEIRO QUIJADA, 2015). 
Por ello, se hace necesario llevar a cabo acciones que abunden en la consideración patrimonial de estos edificios yendo más allá de las vinculaciones con el periodo en que se construyeron. La valoración objetiva de estos bienes se presenta indispensable en este cometido (PLAN, 2015: 19), pues realmente suponen una expresión contemporánea que ha ido traspasando los cambios de sistemas de gobierno del convulso siglo XX. Podría atenderse a otros valores intrínsecos de esta arquitectura bien sean por autenticidad, autoría, etc. (COSTA, 1999: 9), por la importancia del contexto y entorno en que se insertan (MOSQUERA ADELL; PÉREZ CANO, 2011: 409), o ampliando la óptica a lo que esta arquitectura supuso en el germen y construcción de la Unión Europea, cuya pérdida podría ahondar en el menoscabo de una identidad colectiva como así se hace patente en la Recomendación (91) 13 del Comité de Ministros de la Unión Europea (GONZÁLEZ MARTÍNEZ, 2013).

Esta arquitectura no solo sobrevivió a la época dictatorial y se consolidó en España -y en el resto de Europadurante dicha etapa, sino que su asentamiento supuso la base para otras expresiones tardías en torno a la misma a lo largo de la etapa final del siglo XX. Esta pervivencia a través de los cambios de sistemas experimentados, desde la Segunda República, pasando por la Dictadura hasta llegar a la democracia actual, merecería ser tenida en cuenta en la articulación de unos valores patrimoniales que vayan más allá de la etapa en que se construyó.
- DECLARACIÓN de Praga. Resolución para la protección de los monumentos culturales de los siglos XIX y XX, de 8 de octubre de 1971. Praga: Comisión de Resolución, 1971

- FERNÁNDEZ-BACA CASARES, R.; PÉREZ ESCOLANO, V. (coord.) (2012) Cien años de arquitectura en Andalucía. El Registro Andaluz de Arquitectura Contemporánea, 1.900-2.000 [en línea] Sevilla: Instituto Andaluz de Patrimonio Histórico, $2012<$ https://juntadeandalucia.es/export/drupaljda/RAACWEB_0.pdf> [Consulta: 04/12/2018]

- GONZÁleZ MARTínEZ, P. (2013) Aspectos Legislativos del Plan Nacional de Conservación del Patrimonio Cultural del Siglo XX. Madrid: Ministerio de Educación, Cultura y Deporte, Instituto del Patrimonio Cultural de España, 2013

- LEY 2/2017, de 28 de marzo, de Memoria Histórica y Democrática de Andalucía. Boletín Oficial de la Junta de Andalucía, n. ${ }^{\circ}$ 63, de 3 de abril de 2017

- MOSQueRA ADELL, E.; PÉREZ CANO, M. T. (2011) Refugios conocidos. De patrimonio de los arquitectos a patrimonio de todos. En DOMINGO, M.; MUÍNAA, I. (dir.) Criterios de Intervención en el Patrimonio Arquitectónico del Siglo XX. Conferencia Internacional CAH2OthC. Documento de Madrid 2011. Madrid: Ministerio de Cultura, Secretaría General Técnica-Subdirección General de Publicaciones, Información y Documentación, 2011, pp. 403-410

- PLAN Nacional de Conservación del Patrimonio Cultural del siglo XX (2015) Madrid: Ministerio De Educación, Cultura y Deporte, Secretaría General Técnica, Subdirección General de Documentación y Publicaciones, 2015

- QUEIRO QUIJADA, R. (2015) Patronato Municipal y Real Patronato de Casas Baratas de Sevilla. Aportaciones a la conformación de la ciudad a través de la vivienda social. 1913-1986 [en línea] Tesis doctoral inédita, Universidad de Sevilla, 2015 <http://hdl.handle.net/11441/36284> [Consulta: 19/02/2018]

\section{BIBLIOGRAFÍA}

- CostA, X. (1999) La coordinación internacional del proyecto de documentación y conservación del MOVIMIENTO MODERNO. En VV. AA. La arquitectura moderna en Andalucía: un patrimonio por documentar y conservar. La experiencia DOCOMOMO. Sevilla: Consejería de Cultura de la Junta de Andalucía, Instituto Andaluz de Patrimonio Histórico, 1999, pp. 6-11 (Serie Cuadernos, 11)

- DE JONGE, W. (2017) Sleeping Beauty. En KUIPERS, M.; DE JONGE, W. (dir.) Designing from Heritage. Strategies for Conservation and Conversion. Delft: TU Delft - Heritage and Architecture, 2017, pp. 14-29 